\title{
Forgiveness Predictors and Trust in a Digital Age
}

\author{
Meriem Laifa, Bordj Bou Arreridj University, EL Anasser, Algeria \\ Roya Imani Giglou, Institute for Media Studies Catholic University of Leuven, Leuven, Belgium \\ Akrouf Samir, Bordj Bou Arreridj University, EL Anasser, Algeria \\ Ramdane Maamri, University Abdelhamid Mehri - Constantine2, Algeria
}

\begin{abstract}
This article describes how interpersonal relationships structures and standards are evolving. By focusing on a social network context, this study examined different factors that can affect forgiveness decision of a victim of an online offense. In addition, it inspected whether the decrease of trust after an online-related offense can be affected by forgiveness. 323 participants took part in this study by completing a questionnaire that recorded different measurements. Structural equation modeling was used as the main technique for data analysis, and AMOS was used as a tool. Surprisingly, while empathy and commitment had no significant direct effect, results showed that the severity of the offense, its frequency and pretransgression trust are the main factors that influence forgiveness. Moreover, a victim's trust towards the transgressor decreased much more in the absence of forgiveness than in its presence. A valuable contribution of this article is in the prospect for related future research as well as the potential for applications that explore new techniques to facilitate forgiveness in the digital age.
\end{abstract}

\section{KEYWORDS}

Forgiveness, Trust Behavior, Trust Belief, Empathy, Commitment, social Networks

\section{INTRODUCTION}

As individuals are having more access to the Internet and the number of hours they spend online is intensely increasing, Internet-related technologies became crucial tools in people's lives. Integrating these technologies in varied aspects had - and continues to have - a noteworthy impact on societies in different forms. For instance, Facebook became widely used in people's everyday social activities where communities are emerging online, and relationships are initiated, developed and ended. Despite the fact that the digital age's effect on interpersonal relationships is still growing (Anderson \& Rainie, 2010; Hampton, Sessions, Her \& Rainie, 2009; Leggett \& Rossouw, 2014) and the structure and standards of such relationships are evolving, societies are urged to redefine the actions that are publicly applicable and suitable in digital settings.

At the heart of the online social space, trust is considered to play a key role in bolstering successful interactions, which attracted many researchers (Adam \& Spedding, 2007; Whitty \& Joinson, 2008, 
Williams \& Kitchen, 2009). However, in online communications, relationships sometimes go amiss because of an upsetting or hurtful deed even from those we trust the most. While trust between individuals is argued to help resolve conflicts (Lewicki \& Wiethoff, 2006), forgiveness is believed to play a key role in repairing interpersonal relationships after a transgression (Griswold, 2007; Marsh \& Briggs, 2009). Forgiveness has also shown many important benefits like reducing negative emotions (e.g., sadness and anger) and improving individuals' health by lowering blood pressure, stress and depression risks, as well as rising spiritual and psychological welfare (Kelln \& Ellard, 1999). Moreover, studies show that forgiving improves connectedness and cooperation within a community by increasing acceptance and understanding between community members, as well as reducing guilt and strengthening solutions for conflicts (Rusbult, Hannon, Stocker \& Finkel, 2005; Vasalou, Hopfensitz \& Pitt, 2008). Whereas scholars across a variety of disciplines have studied trust in online settings, much less attention has been paid to forgiveness. Nevertheless, many of those who study forgiveness relate it to forgetting, claiming that forgiveness benefits cannot be fully exploited in the digital age when the reminder of the transgression is still present (Ambrose, Friess \& Van Matre, 2012; Mayer-Schönberger, 2011). However, in this study we focus on the most common conception of interpersonal forgiveness instead of forgetting.

By bridging research on trust and forgiveness, we emphasize the need to examine forgiveness in the context in which the conflict occurs and we contribute to the literature in two main ways. First, as there is a lack of studies about forgiveness in the digital age, our study builds upon existing studies to examine if forgiveness can be predicted by the same factors that were proven to affect it in offline settings. In addition, we investigate whether victims' acceptance and involvement in the used social network have a significant impact on their decision to forgive an offense that takes place on that social network. Second, we inspect if the decrease of trust after and offense can be affected by the presence of forgiveness. To achieve these purposes, two surveys were conducted, and hypotheses were tested using structural equation modeling (SEM) approach. We believe that this study will inspire further research for a better understanding of forgiveness in the digital age.

In the following section, we present the theoretical basics of our research hypotheses and questions. We state the methods we used in Section 3. Sections 4 and 5 are devoted to explain different results and discussion of findings, respectively. Finally, we highlight the limitations of the current study and discuss perspectives for future work in Section 6.

\section{THEORETICAL FRAMEWORK}

\section{Forgiveness and Its Factors}

In the literature, forgiveness definitions range from simple ones like "letting go of past hurt and bitterness" (Berecz, 2001, p. 255), to more complicated ones like: a set of pro-social motivational changes that occur after an offense, involving a decrease in negative effects and/or behaviors and an increase in positive ones, towards an offender who does not necessarily deserve these changes (Enright \& Kittle, 1999; McCullough et al., 1998). In our settings we focus on ongoing relationships, so we adopt Rusbult et al. (2005, p. 186) definition for interpersonal forgiveness, that is: "the victim's willingness to resume pre-transgression interaction tendencies - the willingness to forego grudge and vengeance, instead coming to behave toward the perpetrator in a positive and constructive manner".

Many factors affect forgiveness decision directly or indirectly. According to the literature, these factors can be classified into four categories: (1) social cognitive factors (empathy and attribution), (2) offense-specific factors (severity of the offense, its frequency, and the apology of the offender), (3) relationship-specific factors (commitment and closeness), and (4) personal factors (personality traits and religiosity) (Laifa, Akrouf \& Maamri, 2015). However, some factors are more influential 
18 more pages are available in the full version of this document, which may be purchased using the "Add to Cart" button on the product's webpage:

www.igi-global.com/article/forgiveness-predictors-and-trustin-a-digital-age/209746?camid=4v1

This title is available in InfoSci-Technology Adoption, Ethics, and Human Computer Interaction eJournal Collection, InfoSci-Journals, InfoSci-Journal Disciplines Communications and Social Science, InfoSci-Journal Disciplines Computer Science, Security, and Information Technology. Recommend this product to your librarian: www.igi-global.com/e-resources/libraryrecommendation/?id $=153$

Related Content

A Qualitative Study in User's Information-Seeking Behaviors on Web Sites: A User-Centered Approach to Web Site Development Napawan Sawasdichai (2009). Human Computer Interaction: Concepts, Methodologies, Tools, and Applications (pp. 816-849).

www.igi-global.com/chapter/qualitative-study-user-informationseeking/22287?camid=4v1a

A Perception of Prejudice in Face-to-Face Retail Services: Comparative Analyses of Age, Gender, and Appearance

Mirian Palmeira, Denise Palmeira and Cassia Maria dos Santos (2012). International Journal of Applied Behavioral Economics (pp. 22-40).

www.igi-global.com/article/perception-prejudice-face-faceretail/71052?camid $=4 \mathrm{v} 1 \mathrm{a}$ 
Cultural Problems in Applying SSM for IS Development

Trevor T. Moores and Frank H. Gregory (2002). Human Factors in Information

Systems (pp. 104-116).

www.igi-global.com/chapter/cultural-problems-applying-ssm-

development/22435?camid=4v1a

Gender-Based Attitudes Toward Technology

Konrad Morgan and Madeleine Morgan (2009). Human Computer Interaction:

Concepts, Methodologies, Tools, and Applications (pp. 2274-2277).

www.igi-global.com/chapter/gender-based-attitudes-toward-

technology/22383?camid=4v1a 